\title{
Injection-site reactions upon Kineret (anakinra) administration: experiences and explanations
}

\author{
Christina Kaiser • Ann Knight • Dan Nordström • \\ Tom Pettersson · Jonas Fransson • Ebba Florin-Robertsson • \\ Björn Pilström
}

Received: 18 March 2011/Accepted: 21 August 2011/Published online: 1 September 2011

(C) The Author(s) 2011. This article is published with open access at Springerlink.com

\begin{abstract}
Anakinra (Kineret), a recombinant form of human interleukin-1 (IL-1) receptor antagonist, is approved for the treatment of rheumatoid arthritis (RA) in combination with methotrexate. Kineret is self-administered by daily subcutaneous injections in patients with active RA. The mechanism of action of anakinra is to competitively inhibit the local inflammatory effects of IL-1. Kineret is generally safe and well tolerated and the only major treatment-related side effects that appear are skin reactions at the injection site. Due to the relatively short half-life of anakinra, daily injection of the drug is required. This, in combination with the comparably high rates of injection-site reactions (ISRs) associated with the drug, can become a problem for the patient. The present review summarises published data concerning ISRs associated with Kineret and provides some explanations as to their cause. The objective is also to present some clinical experiences of how the ISRs can be managed.
\end{abstract}

Keywords Anakinra $\cdot$ Kineret $\cdot$ Injection-site reactions

\begin{tabular}{|c|c|}
\hline \multicolumn{2}{|c|}{ Abbreviations } \\
\hline IL-1 & Interleukin-1 \\
\hline RA & Rheumatoid arthritis \\
\hline IL-Ra & Interleukin-1 receptor antagonist \\
\hline
\end{tabular}

C. Kaiser $(\square)$ · J. Fransson · E. Florin-Robertsson · B. Pilström Swedish Orphan Biovitrum AB, 11276 Stockholm, Sweden e-mail: Christina.Kaiser@sobi.com

\section{A. Knight}

Department of Rheumatology, Uppsala University Hospital, 75185 Uppsala, Sweden

D. Nordström · T. Pettersson

Division of Rheumatology and Internal Medicine, Helsinki

University Central Hospital, 00290 Helsinki, Finland
ISR Injection-site reaction

DMARD Disease-modifying anti-rheumatic drug

\section{Background}

Anakinra is a recombinant form of the human interleukin-1 receptor antagonist (IL-1Ra), r-metHuIL-1Ra, which is produced by recombinant DNA technology in an E. coli expression system. Anakinra is identical to native human IL-1Ra, except for the addition of a single methionine residue at its amino terminus [1]. Therapeutically, anakinra neutralises the biological activity of IL- $1 \alpha$ and $\beta$ by competitively inhibiting the two cytokines binding to the IL-1 receptor [2]. The maintenance of balance between IL-1 and IL-1Ra is thought to be important in preventing the development of inflammatory arthritis. Kineret is indicated for the treatment of rheumatoid arthritis in adult patients, in the European Union in combination with methotrexate in patients with inadequate response to methotrexate alone, in the United States also as monotherapy in patients failing at least one disease-modifying anti-rheumatic drug (DMARD). The recommended dose of Kineret is $100 \mathrm{mg}$ administered once daily via subcutaneous injection.

Injection-site reactions (ISR), often defined as a constellation of symptoms including swelling, erythema, pruritus and pain around the site of injection, is a common adverse event associated with different kinds of biologic therapies [3], and can present a challenge to patients. ISRs are the most common and consistently reported treatment-related adverse events associated with Kineret. These are typically characterised by one or more of erythema, ecchymosis, inflammation and pain. In a review of five clinical trials, at doses of 50-150 mg/day, the reported rates of ISRs were $71 \%$ for the anakinra-treated 
groups versus $28 \%$ for patients receiving placebo [4]. The median duration of the above-mentioned typical symptoms was 14-28 days. The development of ISRs in patients who had not previously experienced ISRs was uncommon after the first month of therapy. A summary of ISR frequencies in some of the clinical studies with Kineret is presented in Table 1.

\section{Contribution of vehicle constituents to ISRs}

Early observations, in clinical trials with Kineret, indicated that a substantial amount of patients had skin reactions varying in intensity from mild to severe. This prompted studies in both humans and rats in order to investigate if vehicle and/or protein were capable of inducing nonimmunologically mediated cutaneous mast cell degranulation [5]. Healthy volunteers received daily injections of large doses ( $1 \mathrm{ml}$ of up to $200 \mathrm{mg} / \mathrm{ml}$ ) of IL-1Ra for 28 days. Intradermal testing after 28 injections demonstrated that the response (erythema and oedema) for both vehicle alone and rhuIL-1Ra in vehicle generally followed the same pattern as that observed in histamine-injected positive control sites. In rats, an intradermal testing assay was used where extravasation of blue dye (injected in the tail vein) was assessed $30 \mathrm{~min}$ after intradermal injections of test solutions. All test solutions, which consisted of the various components of the Kineret vehicle, induced permeability changes that were significantly greater than those occurring with PBS alone. Changing the vehicle to PBS significantly reduced the reactivity from that occurring with rhuIL-1Ra in citrate buffer. However, the permeability increase was still higher over that occurring with PBS alone. Concurrent administration of diphenhydramine $(100 \mu \mathrm{g})$, an anti-histamine, and rhuIL-1Ra in citrate buffer totally eliminated the permeability increase. Clearly, the results of the study show that the components of the vehicle have the potential to induce mast cell degranulation. But the vehicle is not the sole cause of the reactions since patients given lower doses ( $1 \mathrm{ml}$ of $20 \mathrm{mg} / \mathrm{ml}$ ) of rhuIL-1Ra in vehicle have milder reactions. Thus, the combination of vehicle constituents and a high protein concentration in the syringe give rise to mast cell degranulation upon subcutaneous injection [5]. In one of the dose-finding studies with Kineret [6], it was also noted that the injection-site reactions were dose related. ISRs were experienced by $28 \%$ of subjects in the placebo group and by 19 , $38,56,64$ and $63 \%$ in the groups receiving anakinra at $0.04,0.1,0.4,1.0$ and $2.0 \mathrm{mg} / \mathrm{kg}$, respectively.

The placebo used in all clinical trials performed with Kineret has consisted of the vehicle, i.e. the formulated solution without protein. A considerable amount of patients receiving placebo have also reported ISRs (see above). In commercially available Kineret syringes, anakinra is formulated in $10 \mathrm{mM}$ sodium citrate, $140 \mathrm{mM} \mathrm{NaCl}, 0.5 \mathrm{mM}$ EDTA, and polysorbate 80 and has $\mathrm{pH}$ 6.5. The protein concentration in the Kineret syringe is $100 \mathrm{mg} / 0.67 \mathrm{ml}$,

Table 1 Published clinical trials with Kineret

\begin{tabular}{|c|c|c|c|c|c|c|}
\hline Reference & $\mathrm{N}$ & Therapy $^{\mathrm{a}}$ & $\begin{array}{l}\text { Frequency of IRSs } \\
\text { for each dose }(\%)\end{array}$ & Concomitant drug use & $\begin{array}{l}\text { Withdrawal } \\
\text { rate }\end{array}$ & Dose \\
\hline $\begin{array}{l}\text { Bresnihan } \\
\text { et al. [24] }\end{array}$ & 472 & Mono & $25,50,73,81$ & NSAID, $\sim 85 \%$; corticosteroid $\sim 45 \%$ & $\begin{array}{l}5 \% \text { in } \\
150 \mathrm{mg} / \text { day } \\
\text { dose }\end{array}$ & $\begin{array}{l}\text { Placebo, } 30,75, \\
150 \mathrm{mg} / \text { day }\end{array}$ \\
\hline $\begin{array}{l}\text { Nuki et al. } \\
\text { [25] }\end{array}$ & 309 & $\begin{array}{l}\text { Mono, } \\
\text { extension }\end{array}$ & $\begin{array}{l}\text { Similar to initial } \\
24 \text { weeks }\end{array}$ & As above & As above & As above \\
\hline $\begin{array}{l}\text { Cohen et al. } \\
{[6]}\end{array}$ & 419 & $\begin{array}{r}\text { Combo } \\
\text { MTX }\end{array}$ & $28,19,38,56,64,63$ & NSAID, $\sim 70 \%$; corticosteroid $\sim 45 \%$ & $\begin{array}{l}10 \% \text { in } \\
2.0 \mathrm{mg} / \mathrm{kg} \\
\text { dose }\end{array}$ & $\begin{array}{l}0.04,0.1,0.4 \\
1.0,2.0 \mathrm{mg} / \mathrm{kg}\end{array}$ \\
\hline $\begin{array}{l}\text { Fleischmann } \\
\text { [26] }\end{array}$ & 1399 & Combo & $\sim 70$ & $\begin{array}{l}\text { NSAID, } 86 \% \text {; corticosteroid, } 61 \% \text {; MTX, } \\
59 \% \text {; other DMARDS, } 48 \%\end{array}$ & nd & $100 \mathrm{mg} /$ day \\
\hline $\begin{array}{l}\text { Cohen et al. } \\
{[27]}\end{array}$ & 506 & $\begin{array}{r}\text { Combo } \\
\text { MTX }\end{array}$ & 24,65 & NSAID, $\sim 75 \%$; corticosteroid $\sim 52 \%$ & $8.4 \%$ & $100 \mathrm{mg} /$ day \\
\hline $\begin{array}{l}\text { Fleischmann } \\
\text { et al. [28] }\end{array}$ & 1346 & Combo & $\begin{array}{l}\text { Exposure adjusted } \\
\text { event rates, EAE }\end{array}$ & $\begin{array}{l}\text { NSAID, 87\%; corticosteroids, 58\%; MTX, } \\
54 \% \text {; other DMARDS, 78\% }\end{array}$ & EAE rate & $100 \mathrm{mg} /$ day \\
\hline $\begin{array}{l}\text { den Broeder } \\
\text { et al. [14] }\end{array}$ & 150 & Combo & 36 & $\begin{array}{l}\text { Corticosteroids, 46\%; DMARDS } 54 \% \\
\text { (MTX, 35\%) }\end{array}$ & None & $100 \mathrm{mg} /$ day \\
\hline $\begin{array}{r}\text { Karanikolas } \\
\text { et al. [15] }\end{array}$ & 128 & Combo & 29 & $\begin{array}{l}\text { NSAIDS, } 52 \% \text {; corticosteroids, } 62 \% \text {; } \\
\text { DMARDS, } 100 \%\end{array}$ & nd & $100 \mathrm{mg} /$ day \\
\hline $\begin{array}{l}\text { Le Loet et al. } \\
\text { [29] }\end{array}$ & 1207 & Combo & 62 & DMARDS, $100 \%$ & $6-10 \%$ & $100 \mathrm{mg} /$ day \\
\hline
\end{tabular}

${ }^{a}$ Mono mono therapy, Kineret only, Combo combination therapy 
equivalent to $150 \mathrm{mg} / \mathrm{ml}$. Potential reasons for pain upon injection can be related to buffer (citrate), non-physiological $\mathrm{pH}(6.5$ vs. 7.2) and the presence of the surfactant polysorbate 80 .

The formulation strategy is primarily to achieve stability of the protein, and the use of citrate in the Kineret formulation has indeed structural biologic reasons. Highly concentrated IL-1Ra solutions are prone to aggregate at elevated temperature which is due to its predominant $\beta$-barrel structural fold. This protein aggregation can be suppressed by the presence of citrate in the solution. Phosphate, for instance, is an approximately fourfold weaker suppressant than citrate [7]. Sodium citrate is a common buffering agent for parenteral drugs formulated around $\mathrm{pH} 6$ [8]. Furthermore, buffer concentration is a factor that must be considered when designing injectable presentations and low buffer concentrations $(10 \mathrm{mM}$ or lower) are recommended to reduce injection pain caused by buffer components [9].

It has previously been reported that a component part of an epoetin $\alpha$ preparation caused pain after subcutaneous injection. The pain experienced by the patients taking this epoetin $\alpha$ preparation was described as stinging, burning and itching, and it disappeared in most patients within 15 min. Differences in pain scores after subcutaneous injection of the epoetin $\alpha$ solution and its vehicle were assessed in a small trial with 36 volunteers, normal saline serving as placebo control. It turned out that pain scores with the vehicle or its citrate component were significantly higher than saline. The conclusion was that the local pain experienced after subcutaneous administration of the epoetin $\alpha$ solution was mainly due to the citrate component of the buffered solution [10]. In a study on subcutaneous delivery of typical buffers for human growth hormone preparations in humans, $0.3 \mathrm{ml}$ of buffer with sodium citrate caused significantly more injection pain when compared to $0.3 \mathrm{ml}$ saline [11].

Another component of the Kineret formulation is polysorbate 80 . This substance is commonly used in many pharmaceuticals for its solubilising and stabilising effects. There are some case reports of patients who developed hypersensitivity reactions to erythropoietin. The subsequent skin testing and clinical course suggested that the reactions were due to the excipient polysorbate 80 [12]. Hence, in patients who develop hypersensitivity reactions after subcutaneous injections of biological drugs, a control of the presence of polysorbate 80 is valid.

\section{Clinical experiences}

The clinical experience indicates that there are two different types of ISRs in relation to injections of Kineret.
One immediate, with a stinging and burning feeling, and one delayed, which presents with rash, swelling and pain. Up to $70 \%$ of patients experience an ISR and of those $95 \%$ are mild to moderate in severity. Onset of ISRs are generally within the first weeks of initiating therapy, and patients who do not experience an ISR within 4 weeks are unlikely to experience any ISR. The incidence rate of ISRs tends to diminish when patients are on concomitant oral steroids [13-15].

The delayed type can present with a more severe reaction involving erythema, pruritus, swelling and pain, i.e. inflammatory lesions. Five patients were reported with cutaneous drug reactions due to anakinra in 2005 [16]. A histopathological study was performed on punch biopsy specimens of skin lesions. Within the dermis, the most striking feature was a prominent eosinophilic infiltrate with a tendency to concentrate around vessels and surrounding nerve fibres. An increased number of spindle-shaped mast cells and CD68+ dermal macrophages was also seen, characteristic of an allergic inflammation. The drug was discontinued in two patients (systemic reaction in one) while the other three completed the period of study but had occasional reappearances of drug eruptions. The delayed reaction may be treated with topical corticosteroids or antihistamines and, in the vast majority of cases, disappears within 2 months.

The immediate ISRs with acute pain, experienced by many patients, cannot to the same extent be relieved by the remedies mentioned above. This reaction may, however, be alleviated by placing a cool pack on the injection site for a few minutes before and after the injection, thereby mildly anaesthetising the subcutaneous nerves. Many physicians assert that the immediate reaction is the one which is hardest to endure and is the cause of many drop outs from treatment with Kineret.

At our clinics (Nordström, Pettersson and Knight), we recently conducted a placebo-controlled trial with anakinra in adult-onset Still's disease. During this study, patients were asked to apply a cool pack before and after the injection and to warm the syringe in their hand before injecting. Over $50 \%$ out of 12 patients experienced mild ISRs, all of whom required or were offered antihistamines and/or topical corticosteroids. Only one patient experienced an intermediate ISR that subsided during followup, and no patient withdrew from the study because of ISRs.

\section{Remedies to relieve ISRs}

The clinical experiences put together can aid in the recommendation of remedies for the different kinds of ISRs. As described above, to alleviate the acute pain (stinging, 
burning) it is advised to warm the syringe, with its content, to room temperature before the injection and to apply a cold pack to the injection site 2-3 min before and immediately after the injection. The delayed reactions can be mitigated by application of topical hydrocortisone or anti-histamine cream, and it is recommended to alternate the injection sites to avoid recall reactions. The clinical understanding is also that they will disappear over time. In our opinion, the single most important measure to make patients manage both the acute and delayed ISRs is to inform in advance about the potential for such reactions. Convincing patients to remain motivated to push beyond the weariness of injections and injection-site reactions can be challenging, and these challenges have a major impact on adherence. This has been particularly true for patients suffering from multiple sclerosis, where disease-modifying therapies are often burdened with ISRs [17].

\section{Discussion}

ISRs related to some anti-TNF $\alpha$ therapies

Among other biological therapies, also the TNF $\alpha$-inhibitors are burdened with ISRs. Among patients receiving e.g. Humira (adalimumab) and Enbrel (etanercept) typically 10-20\% report ISRs [18]. Reactions to both therapies are considered to be of the delayed type. The majority of dermal infiltrate at the site of injection is composed of $\mathrm{CD} 4+\mathrm{T}$ cells $(\mathrm{CD} 8+\mathrm{T}$ cells in recall reactions), indicating a lymphocyte-mediated hypersensitivity reaction. The ISRs present the first month of treatment and usually decrease in frequency with the continuation of therapy [18]. In one case report for Enbrel, the histologic findings differed considerably from the well-characterised Enbrel ISRs reported in the literature. The dermal changes were those of eosinophilic cellulitis, unlike the lymphocyte-rich infiltrates seen in typical ISRs. The predominance of eosinophils would point towards a role for IL-5 and a mechanism more akin to a $\mathrm{TH} 2$ reaction. It was suggested that the ISRs in this patient could be explained by the rheumatoid factor autoantibody binding to the $\operatorname{IgG} \mathrm{Fc}$ component found in both Enbrel and Humira, since the patient two weeks earlier had experienced the same type of reaction against Humira [19]. In studies with Cimzia (certolizumab pegol), the only PEGylated TNF $\alpha$-inhibitor, the overall tolerability profile was similar to those of other anti-TNF $\alpha$ agents but injection-site reactions were less frequent and mild to moderate in nature. The inference made was that the PEG-moiety inhibited non-immune stimulated degranulation of mast cells which may explain the low level of ISRs seen with this therapy [20].
Immunological clues

In vitro studies have shown that H1-blocking antihistamines reduce the release of proinflammatory mediators from mast cells and basophils and also reduce the chemotaxis and activation of inflammatory cells (especially eosinophils) and the expression of adhesion molecules induced by immunological and non-immunological stimuli in epithelial cell lines [21]. Throughout the course of allergic inflammation, the functional interface between mast cells and eosinophils, which can be mediated by soluble factors, is important in modulating the severity and/ or duration of the allergic response [22].

It is noteworthy that citric acid has been found to activate mast cells and cause airway constriction in guinea pigs, and the subsequent analysis of BAL (bronchoalveolar lavage) fluid showed increased levels of histamine [23]. This is in accordance with the findings by Bendele et al. in 1995, reporting that the combination of vehicle constituents and high protein concentration in the Kineret formulation caused mast cell degranulation upon subcutaneous injection in rats and that this could be prevented by concomitant injection of diphenhydramine. The clinical observations that both the immediate and, principally, the delayed type of injection-site reactions can be alleviated by topical antihistamines, and corticosteroids can thus be explained along this route.

\section{Conclusion}

The immediate and acute pain experienced by many patients upon Kineret injection is caused by administration of the vehicle constituents in combination with a relatively large amount of anakinra in a highly concentrated protein solution (as described in the 'Background'), causing mast cell degranulation. This reaction can be mitigated by some simple remedies and it is thus very important that the practitioners inform the patients about ISRs and how to manage them. The delayed-type injection-site reactions tend to be transient and can be tolerated by most patients after adequate information. It is crucial to minimise the impact of adverse effects in order to help patients adhere to their treatment regimens.

Conflict of interest The authors declare that they have no conflict of interest. Kaiser, Florin-Robertsson, Fransson and Pilström are employees at Swedish Orphan Biovitrum.

Open Access This article is distributed under the terms of the Creative Commons Attribution Noncommercial License which permits any noncommercial use, distribution, and reproduction in any medium, provided the original author(s) and source are credited. 


\section{References}

1. Zanette D et al (1998) Human IL-1 receptor antagonist from Escherichia coli: large-scale microbial growth and protein purification. J Biotechnol 64(2-3):187-196

2. Arend WP, Gabay C (2000) Physiologic role of interleukin-1 receptor antagonist. Arthritis Res 2(4):245-248

3. Clarke JB Mechanisms of adverse drug reactions to biologics. Handb Exp Pharmacol (196):453-474

4. Mertens M, Singh JA (2009) Anakinra for rheumatoid arthritis: a systematic review. J Rheumatol 36(6):1118-1125

5. Bendele A et al (1995) Cutaneous mast cell degranulation in rats receiving injections of recombinant human interleukin-1 receptor antagonist (rhIL-1ra) and/or its vehicle: possible clinical implications. J Lab Clin Med 125(4):493-500

6. Cohen S et al (2002) Treatment of rheumatoid arthritis with anakinra, a recombinant human interleukin-1 receptor antagonist, in combination with methotrexate: results of a twenty-four-week, multicenter, randomized, double-blind, placebo-controlled trial. Arthritis Rheum 46(3):614-624

7. Raibekas AA et al (2005) Anion binding and controlled aggregation of human interleukin-1 receptor antagonist. Biochemistry 44(29):9871-9879

8. Wang YC, Kowal RR (1980) Review of excipients and pH's for parenteral products used in the United States. J Parenter Drug Assoc 34(6):452-462

9. Fransson J, Espander-Jansson A (1996) Local tolerance of subcutaneous injections. J Pharm Pharmacol 48(10):1012-1015

10. Frenken LA et al (1993) Identification of the component part in an epoetin alfa preparation that causes pain after subcutaneous injection. Am J Kidney Dis 22(4):553-556

11. Laursen T, Hansen B, Fisker S (2006) Pain perception after subcutaneous injections of media containing different buffers. Basic Clin Pharmacol Toxicol 98(2):218-221

12. Steele RH et al. (2005) Hypersensitivity reactions to the polysorbate contained in recombinant erythropoietin and darbepoietin. Nephrology (Carlton) 10(3):317-320

13. Konttinen L et al (2006) Effectiveness of anakinra in rheumatic disease in patients naive to biological drugs or previously on TNF blocking drugs: an observational study. Clin Rheumatol 25(6): 882-884

14. den Broeder AA et al (2006) Observational study on efficacy, safety, and drug survival of anakinra in rheumatoid arthritis patients in clinical practice. Ann Rheum Dis 65(6):760-762

15. Karanikolas G et al (2008) Adjunctive anakinra in patients with active rheumatoid arthritis despite methotrexate, or leflunomide, or cyclosporin-A monotherapy: a 48-week, comparative, prospective study. Rheumatology (Oxford) 47(9):1384-1388
16. Vila AT et al (2005) Adverse cutaneous reactions to anakinra in patients with rheumatoid arthritis: clinicopathological study of five patients. Br J Dermatol 153(2):417-423

17. Saunders $C$ et al. Factors that influence adherence and strategies to maintain adherence to injected therapies for patients with multiple sclerosis. J Neurosci Nurs 42(5 Suppl):S10-S8

18. Moustou AE et al (2009) Cutaneous side effects of anti-tumor necrosis factor biologic therapy: a clinical review. J Am Acad Dermatol 61(3):486-504

19. Winfield $\mathrm{H}$ et al (2006) Eosinophilic cellulitislike reaction to subcutaneous etanercept injection. Arch Dermatol 142(2): $218-220$

20. Rivkin A (2009) Certolizumab pegol for the management of Crohn's disease in adults. Clin Ther 31(6):1158-1176

21. Assanasen P, Naclerio RM (2002) Antiallergic anti-inflammatory effects of H1-antihistamines in humans. Clin Allergy Immunol $17: 101-139$

22. Minai-Fleminger Y, Levi-Schaffer F (2009) Mast cells and eosinophils: the two key effector cells in allergic inflammation. Inflamm Res 58(10):631-638

23. Lin CH, Lai YL (2005) Mast cell mediators in citric acid-induced airway constriction of guinea pigs. Toxicol Appl Pharmacol 206(3):343-350

24. Bresnihan B et al (1998) Treatment of rheumatoid arthritis with recombinant human interleukin-1 receptor antagonist. Arthritis Rheum 41(12):2196-2204

25. Nuki G et al (2002) Long-term safety and maintenance of clinical improvement following treatment with anakinra (recombinant human interleukin-1 receptor antagonist) in patients with rheumatoid arthritis: extension phase of a randomized, double-blind, placebo-controlled trial. Arthritis Rheum 46(11):2838-2846

26. Fleischmann RM (2003) Addressing the safety of anakinra in patients with rheumatoid arthritis. Rheumatology (Oxford) 42(Suppl 2):ii29-35

27. Cohen SB et al (2004) A multicentre, double blind, randomised, placebo controlled trial of anakinra (Kineret), a recombinant interleukin 1 receptor antagonist, in patients with rheumatoid arthritis treated with background methotrexate. Ann Rheum Dis 63(9): 1062-1068

28. Fleischmann RM et al (2006) Safety of extended treatment with anakinra in patients with rheumatoid arthritis. Ann Rheum Dis 65(8): 1006-1012

29. Le Loet $X$ et al (2008) Effect of anakinra on functional status in patients with active rheumatoid arthritis receiving concomitant therapy with traditional disease modifying antirheumatic drugs: evidence from the OMEGA trial. J Rheumatol 35(8):1538-1544 